\title{
APLICAÇÃO DE NIACINA OU TIAMINA PROMOVEM INCREMENTO NO DESENVOLVIMENTO DE MOSTARDA
}

\author{
Eduardo Pradi Vendruscolo ${ }^{1 *}$, Paulo Ricardo de Oliveira ${ }^{2}$, Alexsander Seleguini ${ }^{3}$
}

\footnotetext{
${ }^{1}$ Eng. Agrônomo; Doutorando do Programa de Pós-graduação em Agronomia (PPGA), Escola de Agronomia, Universidade Federal de Goiás (EA/UFG), Av. Nova Esperança, s/n, Campus Samambaia, 74690-900, Goiânia, GO, Brasil. *E-mail: agrovendruscolo@ gmail.com

${ }^{2}$ Discente do Curso de Agronomia, Escola de Agronomia, Universidade Federal de Goiás (EA/UFG), Av. Nova Esperança, s/n, Campus Samambaia, 74690-900, Goiânia, GO, Brasil.

${ }^{3}$ Eng. Agrônomo, Professor Campus Universitário de Iturama, Universidade Federal do Triângulo Mineiro (UFTM), Iturama, MG, Brasil
}

RESUMO: Estresses causados por fatores bióticos e abióticos podem comprometer o desenvolvimento e a produtividade de espécies de interesse agronômico. Assim, estudos vêm sendo desenvolvidos a fim melhorar as condições de cultivo pela utilização de compostos benéficos, dentre os quais se encontram as vitaminas. O presente trabalho objetivou avaliar os efeitos da aplicação, via solo, de diferentes concentrações de tiamina e niacina sobre o desenvolvimento de plantas de mostarda crespa, cultivada entre os meses de outubro e dezembro na região de Goiânia, Goiás. Dois experimentos, ambos em delineamento de blocos casualizados, compostos por seis tratamentos definidos pela aplicação de $3 \mathrm{~mL}$ de solução contendo diferentes concentrações de niacina ou tiamina $\left(0 ; 200 ; 400 ; 600 ; 800 ; 1000 \mathrm{mg} \mathrm{L}^{-}\right.$ ${ }^{1}$ ). Aos 45 dias após a semeadura foi avaliado o teor relativo de clorofila "a", "b" e total, número de folhas, área foliar, massa fresca e massa seca da parte aérea. Observou-se que a aplicação de ambas as vitaminas incrementou as características biométricas área foliar, massa fresca e massa seca de plantas. O número de folhas foi incrementado com a aplicação da niacina, enquanto que os teores relativos de clorofila foram alterados pela utilização da tiamina. Concluiu-se que a aplicação de tiamina ou de niacina via solo promove incremento das características biométricas e dos teores relativos de clorofila "a" e total da mostarda crespa.

Palavras-chave: Estresse abiótico. Vitamina B1. Vitamina B3. Brassica juncea L.

\section{APPLICATION OF NIACIN OR THIAMINE PROMOTES INCREASE IN MUSTARD DEVELOPMENT}

\begin{abstract}
Stress caused by biotic and abiotic factors may compromise the development and productivity of species of agronomic interest. Thus, studies have been developed in order to improve the conditions of cultivation by the use of beneficial compounds, among which are the vitamins. The present work aimed to evaluate the effects of different concentrations of thiamine and niacin on the development of mustard plants cultivated between October and December in the region of Goiânia, Goiás, Brazil. Two experiments in a randomized blocks scheme were composed of six treatments defined by the application of $3 \mathrm{ml}$ of solution
\end{abstract} Cultura Agronômica, Ilha Solteira, v.26, n.3, p.433-442, 2017 
containing different concentrations of niacin or thiamine $\left(0 ; 200,400,600,800,1000 \mathrm{mg} \mathrm{L}^{-}\right.$ $\left.{ }^{1}\right)$. At 45 days after sowing, the relative content of "a", "b" and total chlorophyll, number of leaves, leaf area, fresh mass and shoot mass were evaluated. It was observed that the application of both vitamins increased the biometric characteristics of leaf area, fresh and dry weight of plants. The number of leaves was increased with the application of niacin, while the relative levels of chlorophyll were altered by the use of thiamine. It was concluded that the application of thiamine or niacin via soil promotes an increase in the biometric characteristics and the relative levels of "a" and total chlorophyll of mustard.

Key words: Abiotic stress. Vitamin B1. Vitamin B3. Brassica juncea L.

\section{INTRODUÇÃO}

Cultivos hortícolas possuem grande importância socioeconômica devido às características do sistema produtivo. Em sua maioria, o cultivo de hortaliças é realizado em pequenas propriedades de agricultores familiares, contribuindo para a segurança alimentar e nutricional da população (PRADO; CECÍLIO FILHO, 2016), diversificação da produção e fixação do homem no campo.

Sendo originária de regiões temperadas, a mostarda crespa (Brassica juncea L.) apresenta folhas grandes e ovaladas, espessas, de cor verde-amarelada brilhante, margens serrilhadas e nervuras de tom mais claro, com sabor picante (FILGUEIRA, 2008). Essa espécie demanda temperaturas amenas variando de 15 a $25^{\circ} \mathrm{C}$ durante a fase de crescimento. Assim, para a região Centro-oeste o plantio é indicado durante o período que compreende os meses de março a julho (EMBRAPA, 2010), quando ocorrem as menores médias de temperatura.

No entanto, para a região de Goiânia, no estado de Goiás, há uma tendência de elevação das temperaturas médias, como observado por Luiz et al. (2016) ao estudarem este fator climático durante a série histórica 1961 a 2008. Esse fato poderá comprometer a expressão máxima do potencial produtivo de culturas como as da família das crucíferas, tornando-se essencial o aprimoramento de técnicas de cultivo tais como a aplicação exógena de compostos benéficos, que visem à amenização do estresse causado por efeitos abióticos.

Dentre a grande quantidade de produtos e elementos que vêm sendo empregada para a melhoria das condições produtivas de espécie de interesse comercial, têm se constatado o uso potencial de vitaminas tais como a vitamina B1 (tiamina), que atua nos órgãos vegetais como cofator enzimático em vias metabólicas, incluindo o ciclo de ácido tricarboxílico, glicólise e ciclo das pentoses fosfato (GOYER, 2010). A aplicação exógena desta vitamina pode desencadear mecanismos de defesa contra agentes patogênicos (AHN et al., 2005; BOUBAKRI et al., 2012) ou ainda incrementar o desenvolvimento vegetativo e os índices de produtividade, como observado por Azhar e Khan (2015), em estudo conduzido a partir do tratamento de sementes de mostarda em diferentes concentrações de cloridrato de tiamina.

Cultura Agronômica, Ilha Solteira, v.26, n.3, p.433-442, 2017 
Assim como a vitamina B1, a vitamina B3 ou niacina também atua no metabolismo vegetal. Os efeitos dessa atuação são refletidos no crescimento vegetativo através do alongamento e expansão celular, acúmulo de reservas e melhora das características produtivas frente às condições adversas do ambiente como déficit hídrico e salinidade do solo (ABDELHAMID et al., 2013; EL-BASSIONY et al., 2014).

Neste contexto, o estudo foi desenvolvido com o objetivo de avaliar os efeitos da aplicação, via solo, de diferentes concentrações de tiamina e niacina sobre o desenvolvimento de plantas de mostarda crespa, cultivada entre os meses de outubro e dezembro na região de Goiânia, Goiás.

\section{MATERIAL E MÉTODOS}

Os experimentos foram conduzidos em ambiente protegido, estufa modelo arco, coberto com filme de PVC transparente de $150 \mu$ e tela antiafídica nas laterais, presente na área experimental da Escola de Agronomia da Universidade Federal de Goiás, no município de Goiânia, GO.

Os ensaios foram conduzidos em vasos de 5 litros preenchidos com solo presente na área experimental, o qual apresentou as seguintes características: $\mathrm{Ca}^{2+}=2,0 \mathrm{cmol}_{\mathrm{c}} \mathrm{dm}^{-3}$, $\mathrm{Mg}^{2+}=0,81 \mathrm{cmol}_{\mathrm{c}} \mathrm{dm}^{-3}, \mathrm{~K}^{+}=131,0 \mathrm{mg} \mathrm{dm}{ }^{-3}, \mathrm{P}\left(\right.$ Mehlich I) $=3,5 \mathrm{mg} \mathrm{dm}^{-3}$, Matéria Orgânica= $7,0 \mathrm{~g} \mathrm{dm}^{-3}, \mathrm{Al}^{3+}=0,0 \mathrm{cmol}_{\mathrm{c}} \mathrm{dm}^{-3}, \mathrm{H}+\mathrm{Al}=2,5 \mathrm{cmol}_{\mathrm{c}} \mathrm{dm}^{-3}$ e valores de $\mathrm{pH}\left(\mathrm{CaCl}_{2}\right)=4,6$, $\mathrm{CTC}=5,6 \mathrm{cmol}_{\mathrm{c}} \mathrm{dm}^{-3}, \mathrm{~V} \%=55,7 \%$ (EMBRAPA, 2011). A análise granulométrica do solo apresentou $48 \mathrm{~g} \mathrm{~kg}^{-1}$ de argila na camada 0-0,2m (EMBRAPA, 2009).

Semeou-se de dez sementes/vaso de mostarda Crespa no dia 17 de outubro de 2016. Após a emergência das plântulas foi realizado o desbaste, mantendo-se apenas uma planta por vaso. A irrigação foi realizada de forma manual diariamente.

Não houve ocorrência de doenças, porém foi realizado o controle de pulgões pela aplicação única de inseticida a base de acetamiprido (250 $\mathrm{g} \mathrm{kg}^{-1}$ de i.a.). A adubação foi realizada conforme recomendação para a cultura (PRADO; CECÍLIO FILHO, 2016), baseada na análise do solo.

Foram estudados em dois experimentos distintos os efeitos da aplicação de concentrações crescentes de Niacina e Tiamina em Mostarda Crespa. Para ambos os experimentos foi utilizado o delineamento de blocos casualizados com seis tratamentos, e cinco repetições. As parcelas foram constituídas de uma planta por vaso e os tratamentos constituídos de seis concentrações de Niacina ou Tiamina $\left(0 ; 200 ; 400 ; 600 ; 800 ; 1000 \mathrm{mg} \mathrm{L}^{-}\right.$ ${ }^{1}$ ). Foram aplicados $3 \mathrm{~mL} /$ planta da solução contendo as diferentes concentrações estabelecidas. A aplicação se deu com o uso de pipeta graduada, diretamente no colo das plantas, uma única vez aos cinco dias após a emergência.

Aos 45 dias após a semeadura foi avaliado o teor relativo de clorofila "a", "b" e total da terceira folha a partir do ápice, usando clorofilômetro digital, em seguida realizou-se o corte 
das plantas para obtenção do número de folhas, área foliar, utilizando-se o programa Easyleaf (EASLON; BLOOM, 2014), massa fresca e massa seca da parte aérea. Para obtenção da massa de matéria seca, as folhas foram colocadas em sacos e posteriormente em estufa de circulação de ar à $65^{\circ} \mathrm{C}$, até a obtenção de massa constante.

Os dados resultantes das coletas foram submetidos à análise de variância da regressão para ajustes de modelos que descrevam adequadamente os efeitos do aumento das concentrações das vitaminas.

\section{RESULTADOS E DISCUSSÃO}

Durante a condução do estudo foi constatada umidade relativa do ar média de $70 \%$ e temperatura média de aproximadamente $26^{\circ} \mathrm{C}$ (Figura 1). Essas condições não são favoráveis ao desenvolvimento da mostarda crespa, uma vez que a cultura apresenta melhor desenvolvimento em condições de temperatura amena $\left(15-25^{\circ} \mathrm{C}\right)($ EMBRAPA, 2010).

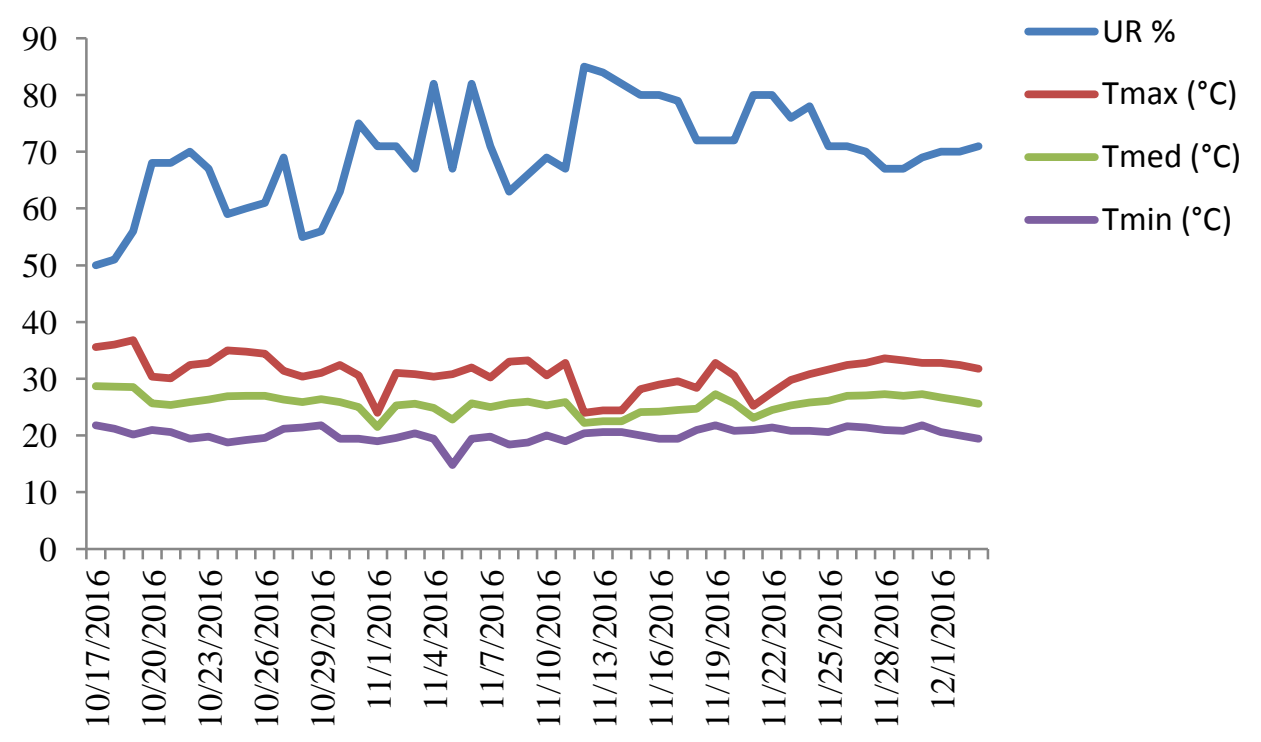

Figura 1. Condições climáticas de umidade relativa do ar e temperatura máxima, média e mínima durante o período de condução do estudo. Goiânia-GO, 2016.

Para o estado de Goiás, assim como para toda a região Centro-oeste, é recomendado o plantio da mostarda entre os meses de março e julho (EMBRAPA, 2010), quando ocorre o período de menores temperaturas e baixa umidade relativa do ar.

Para a massa fresca e seca da parte aérea das plantas de mostarda, verificou-se que o aumento das concentrações de niacina e tiamina nas soluções aplicadas via solo elevaram a massa fresca até o ponto máximo de 54,09 e 53,43 g, obtido com concentração estimada de $485,20 \mathrm{mg} \mathrm{L}^{-1}$ de niacina e 522,59 $\mathrm{mg} \mathrm{L}^{-1}$ de tiamina. Em relação ao tratamento controle, os incrementos foram de $153,18 \%$ e $193,61 \%$ respectivamente.

Cultura Agronômica, Ilha Solteira, v.26, n.3, p.433-442, 2017 
Os pontos máximos de massa seca foram de 5,15 e 4,83 g para a concentração de 508,73 mg $\mathrm{L}^{-1}$ de niacina e $539,70 \mathrm{mg} \mathrm{L}^{-1}$ de tiamina (Figura 2). Nesses pontos máximos os incrementos foram de $123,39 \%$ e $152,11 \%$, respectivamente.

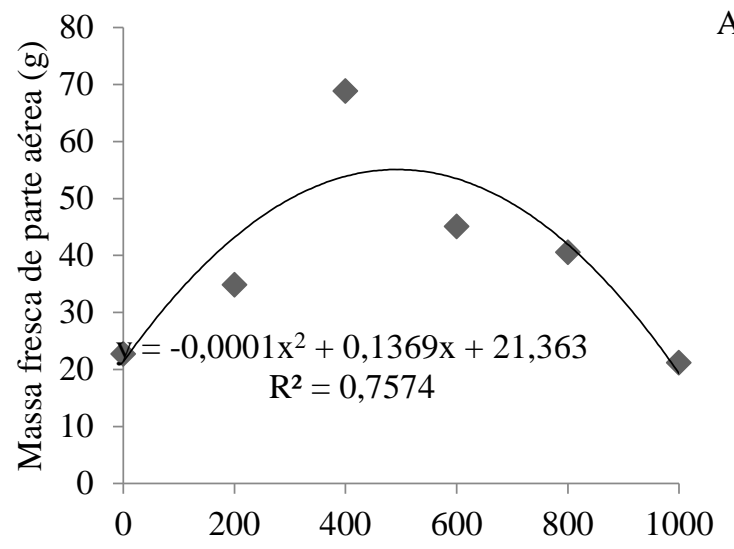

A
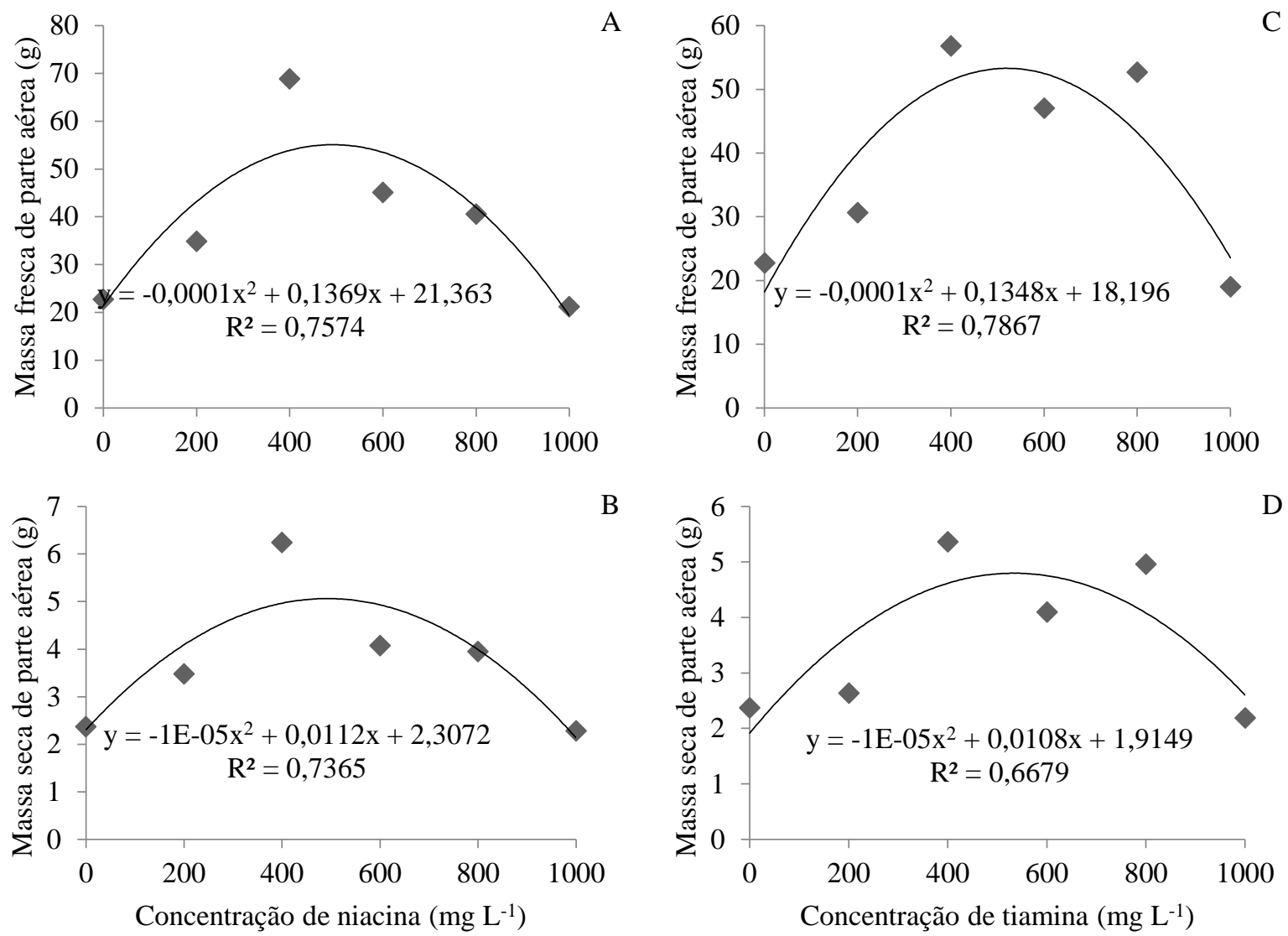

Figura 2. Massa fresca e massa seca de plantas de mostarda submetidas a diferentes concentrações de niacina (A e B) e tiamina (C e D). Goiânia-GO, 2016.

Resultados semelhantes foram obtidos em estudo acerca da aplicação de concentrações crescentes de nicotinamida em plantas de quinoa (Chenopodium quinoa Willd.) cultivada em solo arenoso (ABDALLAH et al., 2016). Os autores observaram incrementos de 25,33, 32,54, 45,93, 18,92, 23,42 e 34,68\% nas variáveis de número de folhas, comprimento da parte aérea, massa fresca da parte aérea, massa seca da parte aérea, massa fresca de raiz e massa seca de raiz, respectivamente, quando compararam o tratamento controle e a aplicação de $100 \mathrm{~g} \mathrm{~L}^{-1}$ de nicotinamida.

Para o número de folhas por planta houve aumento conforme se elevaram as concentrações de niacina até o ponto máximo de $693,25 \mathrm{mg} \mathrm{L}^{-1}$, no qual foram obtidas 8,99 folhas por planta (Figura 3). Essa quantidade de folhas foi superior em 27,21\% à observada em plantas não submetidas às vitaminas. No entanto, houve decréscimo dos teores relativos de clorofila a e total em 10,46\% e 12,34\% até as concentrações de 420,16 e $428,10 \mathrm{mg} \mathrm{L}^{-1}$ de tiamina, sendo que após esses pontos houve elevação dos teores até os valores máximos de 34,72 e 43,86 unidades SPAD, obtidos com a aplicação da maior concentração estudada.

Cultura Agronômica, Ilha Solteira, v.26, n.3, p.433-442, 2017 
Nessa os teores relativos de clorofila a e total foram $9,42 \%$ e $9,73 \%$ superiores àqueles observados no tratamento controle.
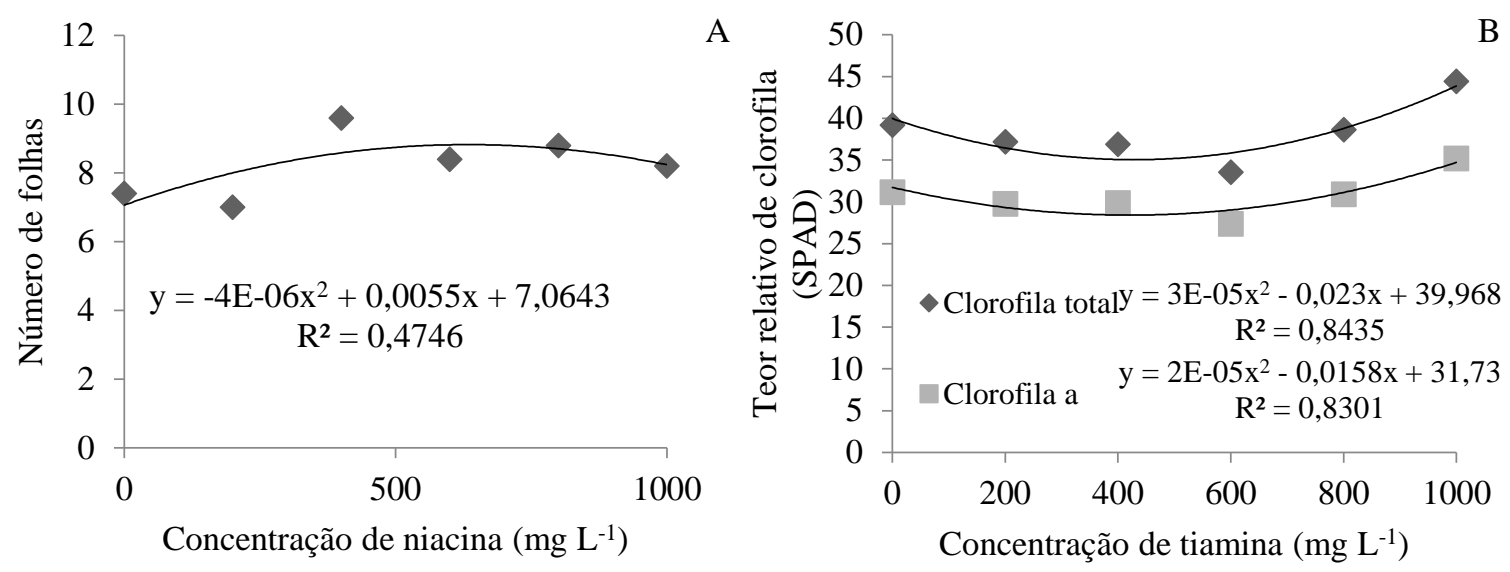

Figura 3. Número de folhas (A) e teor relativo de clorofila (B) em plantas de mostarda submetidas a diferentes concentrações de niacina e tiamina, respectivamente. Goiânia-GO, 2016.

Da mesma forma, verificou-se que a área foliar foi afetada pela aplicação das diferentes concentrações de vitaminas (Figura 4). Constatou-se incremento da área foliar até a concentração máxima de niacina de $501,47 \mathrm{mg} \mathrm{L}^{-1}$ e 518,09 de $\mathrm{mg} \mathrm{L}^{-1}$ de tiamina, para as quais obteve-se uma área foliar de 903,97 e $902,86 \mathrm{~cm}^{2}$ planta $^{-1}$, equivalentes a incrementos de $115,85 \%$ e $140,25 \%$, respectivamente.
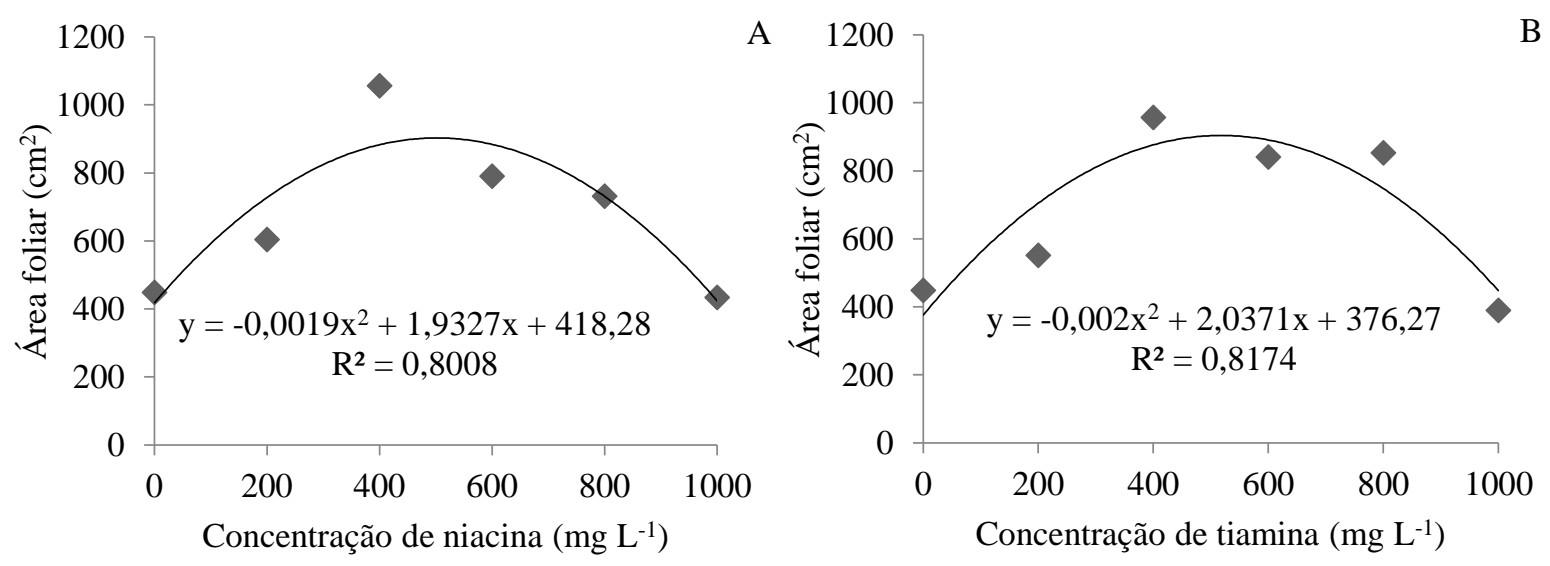

Figura 4. Área foliar de plantas de mostarda submetidas a diferentes concentrações de niacina (A) e tiamina (B). Goiânia-GO, 2016.

Os resultados estão relacionados à aplicação de vitaminas, que pode colaborar para o aumento das atividades metabólicas, favorecendo o crescimento dos vegetais através da melhora na divisão e na expansão celular (EL-BASSIONY et al., 2014). Em complemento, plantas tratadas com vitaminas apresentam aumento do acúmulo de carboidratos nos tecidos (SHI et al., 2002; BARAKAT, 2003; EL-BASSIONY, 2005), os quais podem ser utilizados

Cultura Agronômica, Ilha Solteira, v.26, n.3, p.433-442, 2017 
pelas plantas para a manutenção dos tecidos em períodos a de estresse, como falta de água, por exemplo (PAIXÃO et al., 2014).

Em estudo realizado com a cultura de Calendula officinalis L. a aplicação foliar de soluções de 50 e 100 ppm de tiamina favoreceram o desenvolvimento dos tecidos vegetais, incrementando o número de hastes florais, comprimento das hastes, massa fresca e seca das plantas (SOLTANI et al., 2014). Os autores relacionaram os resultados às ações ligadas ao provimento de melhores condições para o processo de fotossíntese (JALEEL et al., 2007) e a atuação da tiamina durante o metabolismo de carboidratos (HENDAWY; EZZ EL-DIN, 2010).

Assim como a nicotinamida, que participa das atividades metabólicas nas plantas, a tiamina possui fundamental importância como cofator enzimático em vias metabólicas, incluindo o ciclo de ácido tricarboxílico, glicólise e ciclo das pentoses fosfato (GOYER, 2010), mecanismos ligados à produção e fornecimento de energia à planta (PEREIRA et al., 2016).

As vitaminas podem ainda promover a produção de metabólitos secundários, ativação de mecanismos de resistência a estresses bióticos e abióticos, tais como estresse por salinidade, para plantas de milho (HASSANEI et al., 2009), estresse por déficit hídrico em trigo (EL-BASSIONY et al., 2014) e acometimento por doença fúngica em videira (BOUBAKRI et al., 2012) e em arroz (AHN et al., 2005), favorecendo o desenvolvimento dos tecidos.

Apesar de a grande maioria dos estudos fazerem uso da aplicação de vitaminas via foliar ou por imersão de sementes, infere-se que a aplicação via solo é uma alternativa em culturas de interesse econômico tais como espécies hortícolas, para as quais é comumente utilizada irrigação localizada. Isso é possível devido à capacidade de absorção, entre outras substâncias presentes no solo, de vitaminas que são transportadas das raízes aos tecidos aéreos, onde irão manifestar os efeitos sobre as características do vegetal (MOZAFAR; OERTLI, 1992).

Assim, há potencial de utilização das vitaminas como compostos amenizadores do estresse abiótico, possibilitando incrementos significativos no cultivo de espécies, originalmente de climas amenos, nas regiões com clima não favorável à expressão do seu máximo potencial produtivo. No entanto, mais estudos devem ser conduzidos para que recomendações possam ser repassadas aos produtores rurais acerca do comportamento de diferentes espécies e às concentrações de vitaminas a serem utilizadas.

\section{CONCLUSÃO}

A aplicação exógena de tiamina ou niacina pode levar ao incremento no crescimento e concentração de clorofila de mostarda crespa.

Concentrações de tiamina até $518,09 \mathrm{mg} \mathrm{L}^{-1}$ e de niacina até 485,20 $\mathrm{mg} \mathrm{L}^{-1}$ são eficazes na melhoria do desempenho de mostarda crespa. 


\section{REFERÊNCIAS BIBLIOGRÁFICAS}

ABDALLAH, M. M. S.; EL HABBASHA, S. F.; EL SEBAI, T. Comparison of yeast extract and Nicotinaminde foliar applications effect on quinoa plants grown under sandy soil condition. International Journal of PharmTech Research, Mumbai, v. 9, n. 7, p.24-32, 2016.

ABDELHAMID, M. A.; SADAK MERVAT, S. H., SCHMIDHALTER, U., EL-SAADY, A. $M$. Interactive effects of salinity stress and nicotinamide on physiological and biochemical parameters of faba bean plant. Acta Biológica Colombiana, Bogotá, v. 18, n. 3, p.499-510, 2013.

AHN, I. P.; KIM, S.; LEE, Y. H. Vitamin B1 functions as an activator of plant disease resistance. Plant physiology, Rockville, v. 138, n. 3, p.1505-1515, 2005.

AZHAR, S.; KHAN, S. Enhancement of Growth and Yield of Mustard (Brassica Juncea L.) Var. Varuna by Thiamine Hydrochloride (Vitamin-B1) Application. Journal of Functional And Environmental Botany, Nova Deli, v. 5, n. 1, p.24-30, 2015.

BARAKAT, H. O. D. A. Interactive effects of salinity and certain vitamins on gene expression and cell division. International Journal of Agriculture and Biology, Faisalabad, v. 5, n. 3, p.219-225, 2003.

BOUBAKRI, H.; WAHAB, M. A.; CHONG, J.; BERTSCH, C.; MLIKI, A.; SOUSTREGACOUGNOLLE, I. Thiamine induced resistance to Plasmopara viticola in grapevine and elicited host-defense responses, including HR like-cell death. Plant Physiology and Biochemistry, Amsterdam, v. 57, n. 1, p.120-133, 2012.

EASLON, H. M.; BLOOM, A. J. Easy Leaf Area: Automated digital image analysis for rapid and accurate measurement of leaf area. Applications in plant sciences, Washington, v. 2, n. 7, p.1-4, 2014.

EL-BASSIOUNY, H. M. S. Physiological responses of wheat to salinity alleviation by nicotinamide and tryptophan. International Journal of Agriculture and Biology, Faisalabad, v. 7, n. 4, p.653-659, 2005.

EL-BASSIOUNY, H. S. M.; BAKRY, B. A.; ATTIA, A. A. E. M.; AllAh, M. M. A. Physiological role of humic acid and nicotinamide on improving plant growth, yield, and mineral nutrient of wheat (Triticum durum) grown under newly reclaimed sandy soil. Agricultural Sciences, Cambridge, v. 5, n. 8, p.687-700, 2014.

EMBRAPA - Empresa Brasileira de Pesquisa Agropecuária. Catálogo Brasileiro de Hortaliças. Brasília, DF: Embrapa Hortaliças, 2010. 60 p.

EMBRAPA - Empresa Brasileira de Pesquisa Agropecuária. Manual de análises químicas de solos, plantas e fertilizantes. 2. ed. Brasília: Embrapa Informação Tecnológica, 2009. 627 p.

Cultura Agronômica, Ilha Solteira, v.26, n.3, p.433-442, 2017 
EMBRAPA - Empresa Brasileira de Pesquisa Agropecuária. Manual de métodos de análises de solos. 2.ed. Rio de Janeiro: Embrapa Solos, 2011. 230 p.

FILGUEIRA, F. A. R. Novo manual de olericultura: Agrotecnologia moderna na produção e comercialização de hortaliças. Viçosa: UFV. 2008. 421 p.

GOYER, A. Thiamine in plants: aspects of its metabolism and functions. Phytochemistry, Amsterdam, v. 71, n. 14, p.1615-1624, 2010.

HASSANEIN, R. A.; BASSONY, F. M.; BARAKAT, D. M.; KHALIL, R. R. Physiological effects of nicotinamide and ascorbic acid on Zea mays plant grown under salinity stress. 1Changes in growth, some relevant metabolic activities and oxidative defense systems. Research Journal of Agricultural and Biological Sciences, Faisalabad, v. 5, n. 1, p.72-81, 2009.

HENDAWY, S. F.; EZZ EL-DIN A. A. Growth and yield of Foeniculum vulgar var. Azoricum as influensed by some vitamins and amino acids. Ozean Journal Applied Science, Columbus, v. 3, n. 1, p.113-123, 2010.

JALEEL, C. A.; MANIVANNAN, P.; GOMATHINAYAGAM, M.; SRIDHARAN, R.; PANNEERSELVAM, R. Response of antitoxidant potentials in Dioscora rotundata Poir. following paclobutrazol drenching. Comptes Rendus Biologies, Paris, v. 330, n. 11, p.798$805,2007$.

LUIZ, G. C.; CARDOSO, H. C.; RIBEIRO, L. L. Aplicação do teste sazonal de mann kendall na análise de tendência da temperatura e umidade relativa do ar - GOIÂNIA - GO: série histórica 1961 A 2008. Revista Geonorte, Manaus, v. 3, n. 8, p.414-427, 2016.

MOZAFAR, A.; OERTLI, J. J. Uptake and transport of thiamine (Vitamin B1) by barley and soybean. Journal of Plant Physiology, Stuttgart, v. 134, n. 4, p.436-442, 1992.

PAIXÃO, C. L.; JESUS, D. D. S.; AZEVEDO, A. D. Caracterização fisiológica e bioquímica de genótipos de girassol com tolerância diferenciada ao estresse hídrico. Enciclopédia Biosfera, v. 10, n. 19, p.2011-2022, 2014.

PEREIRA, G. P.; ZANETTE, F.; BIASI, L. A.; CARVALHO, R. I. N. D. Respiratory activity of apical meristems of plagiotropic branches of Araucaria angustifolia (Bertol.) Kuntze. Ciência Florestal, Santa Maria, v. 26, n. 1, p.203-211, 2016.

PRADO, R.M.; CECÍLIO FILHO, A.B. Nutrição e adubação de hortaliças. Jaboticabal: FCAV/CAPES, 2016. 600 p.

SHI, H.; XIONG, L.; STEVENSON, B.; LU, T.; ZHU, J. K. The Arabidopsis salt overly sensitive 4 mutants uncover a critical role for vitamin B6 in plant salt tolerance. The Plant Cell, Rockville, v. 14, n. 3, p.575-588, 2002.

SOLTANI, Y.; SAFFARI, V. R.; MOUD, A. A. M. Response of growth, flowering and some biochemical constituents of Calendula officinalis L. to foliar application of salicylic acid,

Cultura Agronômica, Ilha Solteira, v.26, n.3, p.433-442, 2017 
ascorbic acid and thiamine. Ethno-Pharmaceutical Products, Kerman, v. 1, n. 1, p.37-44, 2014. 